\title{
Perspectivas de professores de Física mediante o ensino remoto durante a pandemia de COVID-19
}

\author{
Perspectives of Physics teachers through remote teaching during the COVID-19 pandemic \\ Perspectivas de los profesores de Física a través de la enseñanza remota durante la pandemia \\ COVID-19
}

Recebido: 10/08/2021 | Revisado: 16/08/2021 | Aceito: 18/08/2021 | Publicado: 22/08/2021

\author{
Lilian Felipe da Silva Tupan \\ ORCID: https://orcid.org/0000-0002-6766-1845 \\ Universidade Estadual de Maringá, Brasil \\ Centro Universitário Ingá, Brasil \\ E-mail: prof.liliantupan@uninga.edu.br \\ Glécilla Colombelli de Souza Nunes \\ ORCID: https://orcid.org/0000-0003-0315-717X \\ Universidade Estadual de Maringá, Brasil \\ E-mail: glecillacolombelli@gmail.com \\ Anuar José Mincache \\ ORCID: https://orcid.org/0000-0001-8528-8020 \\ Universidade Estadual de Maringá, Brasil \\ E-mail: anuarfis@ hotmail.com \\ Antonio Oliveira de Souza \\ ORCID: https://orcid.org/0000-0003-1680-9923 \\ Universidade Federal do Oeste da Bahia, Brasil \\ E-mail antonio.oliveira@ufob.edu.br
}

\begin{abstract}
Resumo
A pandemia de COVID-19 mudou completamente o cenário econômico, social e educacional de todo o mundo. A educação foi marcada pela transição do ensino presencial para o ensino remoto, porém toda essa transição ocorreu de forma brusca e repentina e, em muitos casos, os professores não tiveram preparo e tempo hábil para se adaptarem à nova realidade. Dentre as diferentes áreas do ensino as disciplinas das ciências exatas sofrem um impacto relativamente grande nessa transição (presencial * remoto), pois, em geral, são disciplinas que contam em sua maior parte com aulas práticas/expositivas em que se faz uso excessivo do quadro negro para expor equações e resolução de exercícios. Mediante essas dificuldades surge a preocupação com a qualidade do ensino e com o bem-estar psicológico dos professores que, muitas vezes, se veem sobrecarregados para conseguir se adaptar a tais mudanças. Pensando em compreender melhor o panorama do ensino remoto durante a pandemia foi realizada uma pesquisa com professores de física do Ensino médio (EM), Educação de Jovens e Adultos (EJA) e Ensino Superior (ES), que ministram a disciplina de Física em instituições públicas e privadas de todo o Brasil. A fim de compreender sob a perspectiva do professor como ocorreu a transição para as aulas remotas, como tem sido tal experiência e ainda como o docente vê o Ensino de Física pós-pandemia.
\end{abstract}

Palavras-chave: Ensino remoto; Professores; Ensino; Física; COVID-19.

\begin{abstract}
The COVID-19 pandemic has completely changed the economic, social and educational landscapes around the world. Formal education has been marked by the transition from face-to-face to remote education, but all this transition occurred suddenly and unexpectedly and, in many cases, teachers were not prepared and had not enough time to adapt to the new reality. Among the different areas of teaching, the disciplines of the exact sciences field have suffered a serious blow during this transitional period (remote * face-to-face), because, generally speaking, these are the subjects which rely mostly on practical / expository classes, where excessive use of the blackboard is made to demonstrate equations and also for problem solving. Faced with these difficulties, concerns have arisen about the quality of teaching as well as their psychological well-being, as teachers often find themselves overwhelmed, trying to adapt to such changes. Aiming to better understand the landscape of remote education during the pandemic, a survey was conducted with physics teachers from high school (MS), Youth and Adult Education (EJA) and Higher Education (ES), who teach the discipline of Physics in educational institutions as well as public and private companies throughout Brazil, in order to understand, from the teacher's perspective, how the transition to remote classes has developed, how the experience has been like and also how the teacher sees post-pandemic Physics Teaching.
\end{abstract}

Keywords: Remote teaching; Teachers; Teaching; Physics; COVID-19. 


\begin{abstract}
Resumen
La pandemia de COVID-19 cambió por completo el escenario económico, social y educativo en todo el mundo. La educación estuvo marcada por el paso de la enseñanza presencial a la enseñanza a distancia, pero toda esta transición se produjo de forma abrupta y repentina y en muchos casos los docentes no estaban preparados y tenían el tiempo suficiente para adaptarse a la nueva realidad. Entre las diferentes áreas de la educación, las disciplinas de las ciencias exactas sufren un impacto relativamente grande en esta transición (presencial * remoto), ya que generalmente son disciplinas que se apoyan mayoritariamente en clases prácticas / expositivas donde se hace un uso excesivo de la pizarra para exponer ecuaciones y ejercicios de resolución. A través de estas dificultades, existe una preocupación por la calidad de la enseñanza y por el bienestar psicológico de los docentes, que a menudo se encuentran sobrecargados para adaptarse a tales cambios. Con el fin de comprender mejor el panorama de la educación a distancia durante la pandemia, se realizó una encuesta a profesores de física de Bachillerato (EM), Educación de Jóvenes y Adultos (EJA) y Educación Superior (ES), que imparten la disciplina de Física en instituciones públicas y privadas en todo Brasil. Para entender, desde la perspectiva del docente, cómo ocurrió la transición a clases remotas, cómo ha sido dicha experiencia y también cómo ve el docente la Enseñanza de Física pospandémica.
\end{abstract}

Palabras clave: Aprendizaje a distancia; Docentes; Enseñanza; Física; COVID-19.

\title{
1. Introdução
}

O vírus denominado SARS-CoV-2, responsável pela COVID-19, surgiu inicialmente na cidade de Wuhan, na China, e se espalhou rapidamente por todo o mundo, sendo que no dia 11 de março de 2020 a Organização Mundial de Saúde declarou a COVID-19 como pandemia (WHO, 2020; Oliveira et al. 2020).

Por se tratar de um vírus de fácil transmissão e potencialmente perigoso, centenas de países adotaram medidas de distanciamento social (ou até mesmo de lockdown) (Houvèssou, Souza \& Silveira, 2021), como consequência, escolas do ensino regular, faculdades, institutos e universidades de todo o mundo paralisaram suas atividades presenciais e procuraram se adaptar a nova realidade de ensino - o ensino remoto emergencial (Dias \& Pinto, 2020).

Os efeitos da pandemia atingiram a Educação devido às medidas de isolamento social e distanciamento físico, necessários à saúde e continuidade da população. Nesse sentido, foi preciso repensar a forma de ensino, o Ministério da Educação e Cultura (MEC) viabilizou a PORTARIA n” 343/2020 que "Dispõe sobre a substituição das aulas presenciais em meios digitais enquanto durar a situação de pandemia do Novo Coronavírus - COVID-19”, e em seu art. 1: “Autorizar, em caráter excepcional, a substituição das disciplinas presenciais, em andamento, por aulas que utilizem meios e tecnologias de informação e comunicação[...]", posteriormente é publicada a PORTARIA no 544, de 16 de junho de 2020: Dispõe sobre a substituição das aulas presenciais por aulas em meios digitais, enquanto durar a situação de pandemia do novo coronavírus COVID-19, (como se trata de uma pandemia corrente, novas portarias podem estar em vigência, sendo as acimas consideras, pois eram as mesmas em vigor na data de realização do presente trabalho) (Imprensa nacional, 2020).

Nesse sentido, quando as aulas presenciais foram suspensas os docentes enfrentaram o desafio de reelaborar sua prática pedagógica para os processos formativos se manterem cristalinos (Monteiro, 2020; Barbosa, Viegas \& Batista, 2020; Quadros \& Cordeiro, 2020; Machado, 2020)

Sem sombra de dúvidas foi algo inesperado, ninguém estava preparado tecnicamente ou logisticamente. Muita pesquisa, muita dedicação, muitos desafios, novos termos e necessidade - para muitos - de conhecer e aprender a lidar com outras formas de tecnologia da informação. Até então, a internet era uma ferramenta manipulada majoritariamente para divulgar e se ter acesso às novas descobertas nas mais diversas áreas do conhecimento científico, religioso e fílosófico. No contexto da pandemia, além de tudo isso, a web desempenha um papel de valorosa importância, uma vez que, sem esse recurso, seria impossível ministrar aulas e/ou compartilhar atividades remotamente. Assim, os novos desafios impõem o uso de desktops, laptops, celulares, tablets ou símiles para que se permita desenvolver o ensino remoto emergencial (Reis, A.V.S.A; Amaro \& Reis, F., 2020).

Antes de discorrer sobre o ensino remoto emergencial é conveniente destacar que este não é o mesmo que Ensino a

Distância (EaD), indicando os pontos sobrepostos e dissonantes. 
A Educação EaD é uma modalidade que usa a mediação na utilização didático-pedagógica por meio de tecnologias de informação. A Educação on-line, categorizada como ensino remoto emergencial, tem aulas síncronas com interação entre estudantes e docentes. Conforme Paiva (2020), diversos autores defendem que a principal diferença entre Ensino EaD e Educação on-line é a sincronicidade no caso on-line. O ponto comum entre as duas modalidades de Educação é o uso de recursos educacionais digitais explorando as tecnologias eletrônicas (Castro \& Queiroz, 2020).

É oportuno arrazoar que um ponto destoante entre as duas modalidades está no papel do docente. Por exemplo, no ensino remoto emergencial o professor é o único responsável pelo ensino e seu planejamento, enquanto no ensino EaD o professor compartilha tanto o planejamento quanto o ensino com outros profissionais, como tutores (presenciais e/ou a distância) que atuam no processo de mediação aluno-professor (Joye, Moreira \& Rocha, 2020).

Como aponta Joye et al. (2020):

No EaD, a docência é compartilhada com outros especialistas, tais como o designer educacional, os professores conteudistas, os produtores de multimídia, os ilustradores, os gestores de Ambientes Virtuais de Aprendizagem (AVAs), dentre outros. [...] (Joye et al. 2020, p. 14)

Joye et al. também discorrem que o perfil do estudante EaD é diferente do aluno do ensino remoto emergencial:

[...] Na EaD, o aluno tem um perfil andragógico, ou seja, um adulto que possui uma motivação específica para estudar on-line e tem um perfil a priori, autônomo. Já na educação remota, o perfil do aluno é diferente, uma vez que esse é motivado a estudar remotamente em situações emergenciais, tais como conflitos bélicos, calamidades, pandemias, ou pessoas em trânsito ou com necessidades educativas especiais que não podem estar no ensino presencial de modo convencional (Joye et al. 2020, p. 14).

Conforme ressalta Godoi (2016), o público EaD é em sua maioria adultos com idades entre 18 e 33 anos. Já no ensino remoto tem a necessidade de abranger todos os públicos, isto é, ensino fundamental, médio e superior.

Outro ponto proeminente é que no ensino remoto emergencial, em geral, as aulas podem ser totalmente síncronas (aulas on-line e com mesma duração da aula presencial) e, nesse caso, as atividades são entregues por meio digital ou impressas. Por outro lado, na modalidade EaD há momentos presenciais e não presenciais (por exemplo, os alunos podem ir aos polos tirarem dúvidas com os tutores, realizarem provas, dentre outras atividades), sendo que as aulas e as atividades avaliativas podem ocorrer de forma síncronas ou assíncronas (discussão nos fóruns dos ambientes de aprendizagem, por exemplo) (Almeida, 2003; Marasca, 2020).

Sinalizados os pontos incomuns é possível inferir que mesmo docentes que já tinham contato com a Educação EaD se viram em uma nova realidade, sendo importante o processo de adaptação a fim de desenvolver eficazmente suas atividades.

Considerando essa migração no sistema de ensino, algumas perguntas surgem: Qual a melhor plataforma a ser utilizada para práxis das aulas? Como preparar as aulas (quais recursos usar? lousa digital, slides, entre outros). Quanto tempo levará esse preparo? Que tipo de preparo deve existir para que essa transição seja adequada? Como resolver extensos exercícios com equações elaboradas?

Buscando responder essas questões e compreender melhor como se deu essa transição do ensino presencial para o ensino remoto nas aulas de Física, o presente trabalho tem como objetivo entrevistar docentes que atuam nas diversas esferas de ensino no Brasil: (i) compreendendo como se deu o preparo e a execução dessa nova modalidade de ensino, (ii) coletando informações sobre o desenvolvimento das aulas, (iii) bem como as perspectivas na visão do professor para o ensino póspandemia. Com base nas respostas obtidas, o estudo em epígrafe também tem como objetivo lançar uma reflexão a fim de melhorar o preparo das aulas remotas, prospectando a necessidade de continuar nessa modalidade de ensino por mais tempo. Considerando o tamanho da amostra, não é pretensão desse texto realizar inferência estatística, apenas realizar uma análise descritiva dos seus pontos amostrais. 


\section{Metodologia}

O presente trabalho se trata de uma pesquisa de caráter quantitativo e qualitativo, uma vez que quantifica os dados apresentando-os em percentuais (Estrela, 2018, Pereira et al. 2018), mas também os analisa sob aspectos relacionados aos sentimentos e, consequentemente, comportamento do docente mediante sua nova realidade (Godoy, 1995). Para a construção deste trabalho foram realizadas pesquisas bibliográficas acerca da pandemia da COVID-19 bem como as mudanças que esta causou no cenário educacional brasileiro, utilizando plataformas como Google acadêmico, Sciencedirect, Research Gate, Portal de periódicos CAPES, Scielo, entre outras.

Com o intuito de compreender a realidade de professores de Física, experienciando o ensino remoto emergencial, foram elaboradas 21 questões na plataforma do Google Docs. O questionário foi distribuído aos professores de Física de todo o Brasil via e-mail e redes sociais.

Com o questionário espera-se mapear o perfil dos professores participantes (idade, gênero e localidade), compreender como os mesmos têm realizado suas aulas, verificando suas condições de trabalho bem como seu estado psicológico e suas perspectivas quanto à forma como o ensino vem sendo conduzido e ainda sobre sua visão pós-pandemia.

As questões foram diligentes entre os meses de outubro e dezembro de 2020 à professores de Física, que lecionam em instituições públicas e privadas atuando no Ensino Médio, Educação de Jovens e Adultos e no Ensino Superior em todo o território nacional, totalizando 194 entrevistados.

De posse do questionário respondido foi possível caracterizar como ocorreu o preparo dos docentes para lecionarem vivenciando a pandemia, como foi a resposta dos alunos em relação às aulas remotas e ainda qual a visão/sentimentos do professor mediante essa nova realidade.

\section{Resultados e Discussão}

Primeiramente, foi levantado o perfil dos professores, identificando a faixa etária e o gênero. Foram entrevistados professores de todos os estados brasileiros, contudo o maior percentual de participantes foi dos estados do Paraná (18\%), São Paulo (16,8\%) e Rio de Janeiro (14,4\%); acredita-se que o retorno foi maior nesses estados por se tratar do estado de origem da pesquisa (Paraná) e estados vizinhos onde os pesquisadores atuam como parceiros. Nos Gráficos 1 e 2 são apresentados, respectivamente, gênero e faixa etária dos entrevistados.

Gráfico 1: Gênero (em porcentagem) dos professores de Física entrevistados.

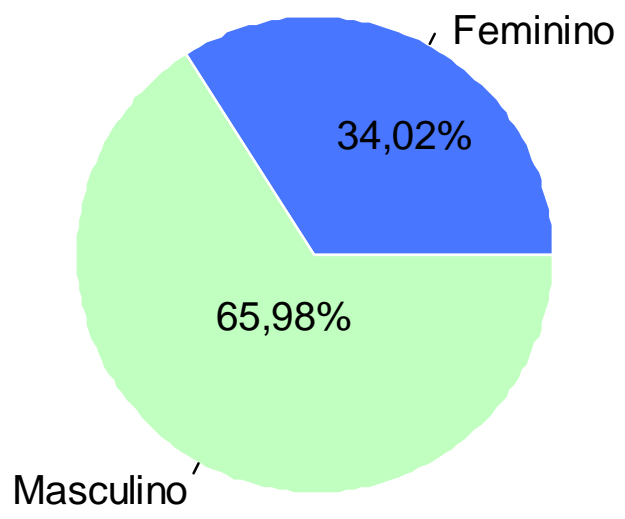

Fonte: Autores (2021). 
Gráfico 2: Faixa etária (em porcentagem) dos professores de Física entrevistados.

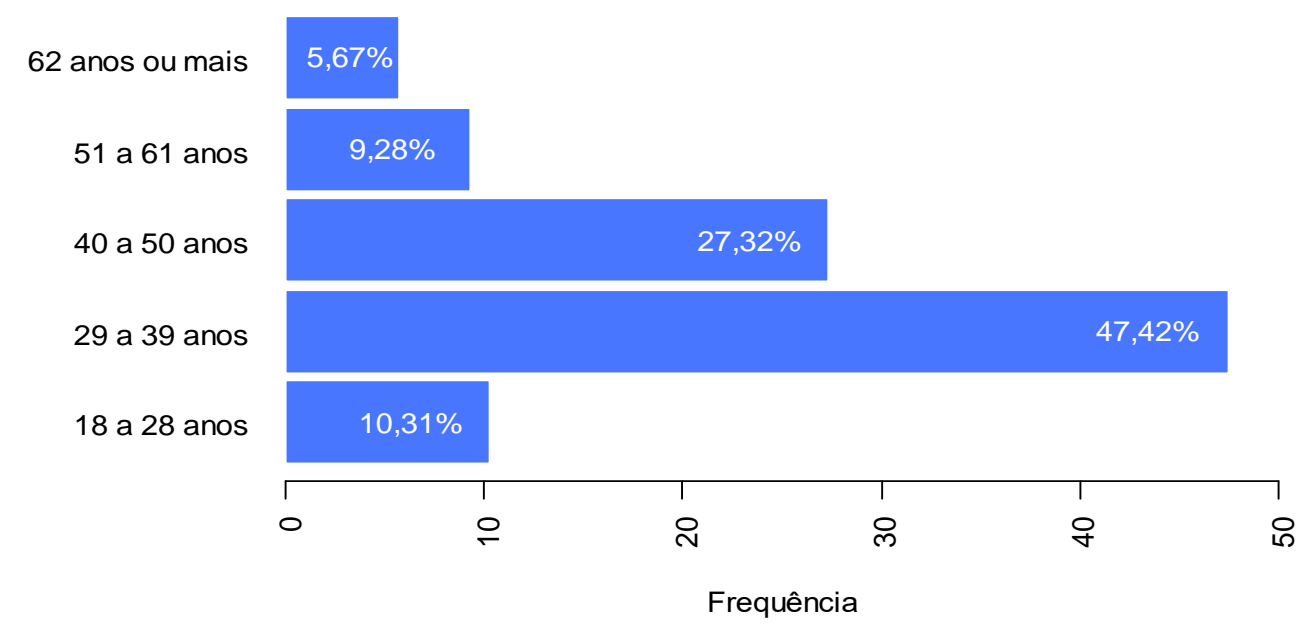

Fonte: Autores (2021).

A partir dos Gráficos 1 e 2 é possível constatar que, em geral, a maior parte dos docentes são do sexo masculino (66 \%) e têm idades entre 29 e 39 anos. A predominância masculina é observada em todas as faixas etárias, mostrando-se expressiva no intervalo etário de 62 anos ou mais, onde culmina um percentual de $95 \%$ dos participantes.

Os entrevistados também foram questionados quanto à esfera do ensino que atuam (Gráfico 3) e se lecionam em instituições públicas ou privadas (Gráfico 4).

Gráfico 3: Demonstrativo da esfera de ensino em que os professores de Física entrevistados atuam.

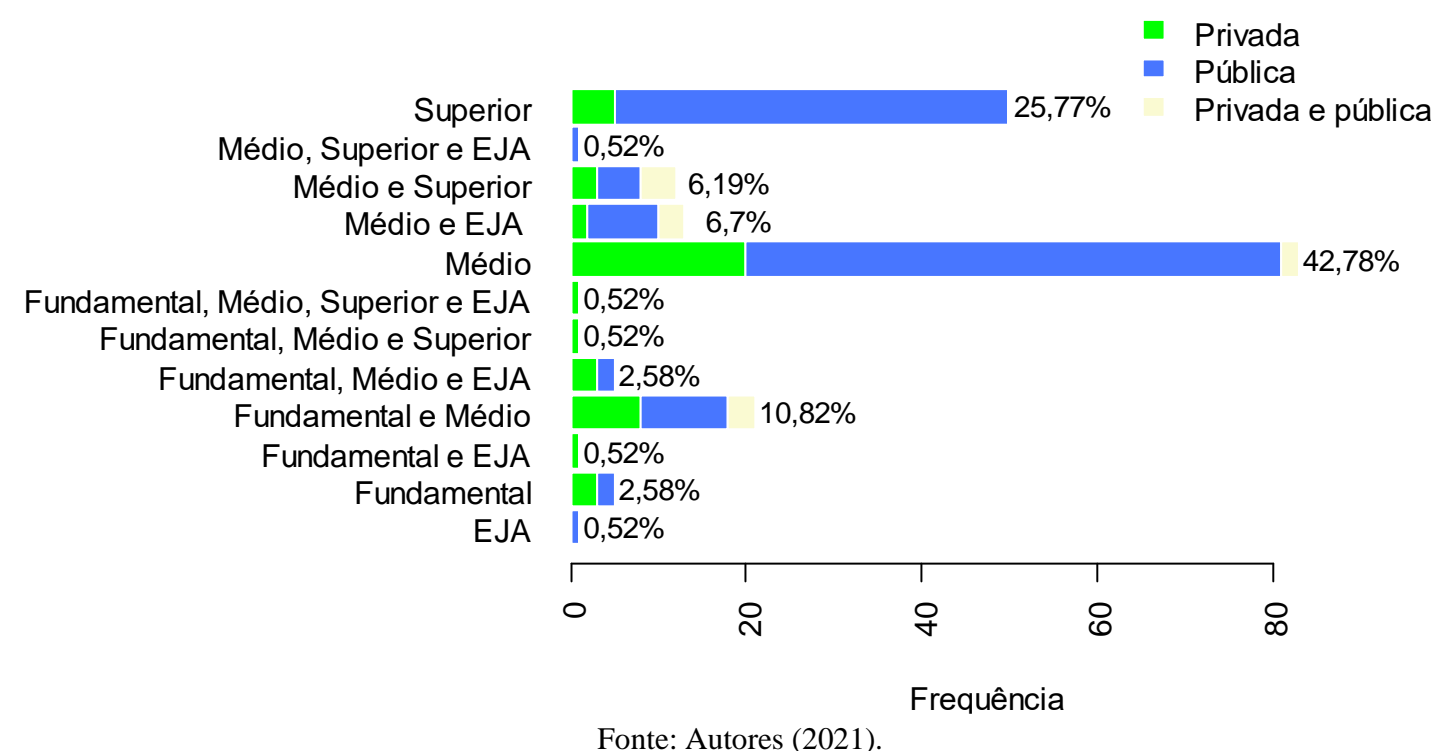


Gráfico 4: Instituições de ensino (pública ou privada) em que os professores de física entrevistados atuam.

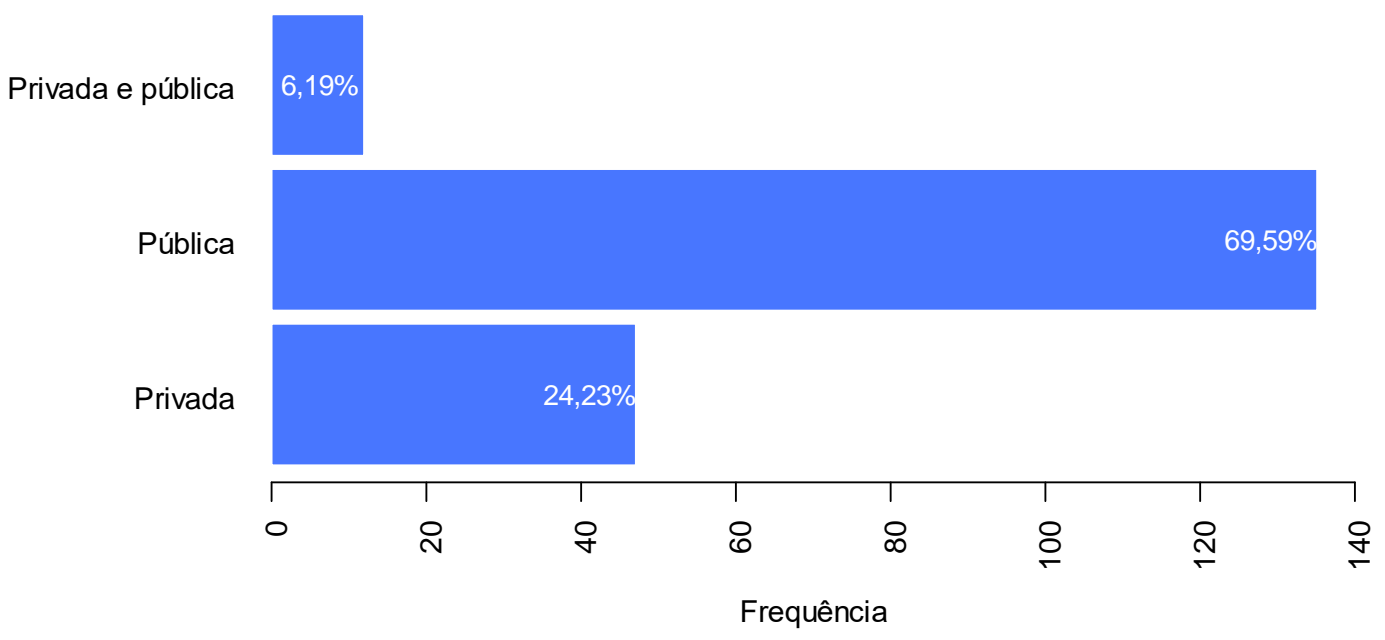

Fonte: Autores (2021).

A partir dos Gráficos 1- 4 infere-se que majoritariamente os docentes são masculinos na faixa etária de 29 a 39 anos, atuam em instituições públicas e lecionam para um público adolescente no Ensino Médio.

$\mathrm{Na}$ sequência os docentes responderam perguntas relacionadas ao preparo, execução e retorno recebido nas aulas remotas. Foram questionados sobre o treinamento recebido, ou seja, se a instituição de ensino forneceu ou não algum tipo de treinamento visando auxiliá-los na transição para o ensino remoto emergencial (Tabela 1), bem como sugerir e capacitar para o uso das plataformas vinculadas às tecnologias digitais.

Tabela 1: Distribuição de frequência do recebimento de treinamento para preparação de aulas remotas com relação ao tipo de ensino.

\begin{tabular}{l|l|l|l|l}
\hline & Privada & Pública & $\begin{array}{l}\text { Privada } \\
\text { Pública }\end{array}$ & Total \\
\hline Não & $30(63,8 \%)$ & $84(62,2 \%)$ & $9(75 \%)$ & $123(63,4 \%)$ \\
\hline Sim & $17(36,2 \%)$ & $51(37,8 \%)$ & $3(25 \%)$ & $71(36,6 \%)$ \\
\hline Total & $47(100 \%)$ & $135(100 \%)$ & $12(100 \%)$ & $194(100 \%)$ \\
\hline
\end{tabular}

Fonte: Autores (2021).

Dentre os docentes de instituições públicas $63 \%$ afirmaram não terem recebido nenhum tipo de treinamento, nas instituições privadas o percentual foi de aproximadamente $64 \%$.

Dos docentes que receberam algum tipo de treinamento (de um total de 79 docentes), Tabela 2, $61 \%$ alegam que o treinamento foi insuficiente para capacitá-los no sentido de se prepararem e executarem suas aulas remotas de forma satisfatória. Desses últimos, $84 \%$ ponderaram que realizaram por conta própria qualificação por meio de cursos, especializações, palestras, webinars, entre outros, a fim de aprender, aprimorar-se ou sanar dúvidas quanto ao uso de plataformas de ensino e outras ferramentas de ensino remoto. (Tabela 3). 
Tabela 2: Distribuição de frequência referente a satisfação do treinamento recebido para preparação de aulas remotas com relação ao tipo de ensino.

\begin{tabular}{l|l|l|l|l}
\hline & Privada & Pública & $\begin{array}{l}\text { Privada } \\
\text { Pública }\end{array}$ & Total \\
\hline Não suficiente & $10(21,3 \%)$ & $35(25,9 \%)$ & $3(25 \%)$ & $48(24,7 \%)$ \\
\hline Suficiente recebeu & $7(14,9 \%)$ & $23(17 \%)$ & $1(8,3 \%)$ & $31(16 \%)$ \\
\hline $\begin{array}{l}\text { Não } \\
\text { treinamento }\end{array}$ & $30(63,8 \%)$ & $77(57 \%)$ & $8(66,7 \%)$ & $115(59,3 \%)$ \\
\hline Total & $47(100 \%)$ & $135(100 \%)$ & $12(100 \%)$ & $194(100 \%)$ \\
\hline
\end{tabular}

Fonte: Autores (2021).

Tabela 3: Distribuição de frequência da procura por conta própria de algum tipo de qualificação (cursos, especializações, palestras, webinars, entre outras) para aprender, aprimorar-se ou sanar dúvidas quanto ao uso de plataformas de ensino e outras ferramentas de ensino remoto com relação ao tipo de ensino.

\begin{tabular}{l|l|l|l|l}
\hline & Privada & Pública & $\begin{array}{l}\text { Privada } \\
\text { Pública }\end{array}$ & Total \\
\hline Não & $11(23,4 \%)$ & $20(14,8 \%)$ & $0(0 \%)$ & $21(16 \%)$ \\
\hline Sim & $36(76,6 \%)$ & $115(85,2 \%)$ & $12(100 \%)$ & $163(84 \%)$ \\
\hline Total & $47(100 \%)$ & $135(100 \%)$ & $12(100 \%)$ & $194(100 \%)$ \\
\hline
\end{tabular}

Fonte: Autores (2021).

Uma vez que o ensino passou a ocorrer de forma remota, o uso de plataformas digitais se fez necessário. Nesse sentido, com base nas respostas enviadas pelos entrevistados construiu-se a Tabela 4 pela ordem de resposta e o Gráfico 5, onde são apresentadas as plataformas mais utilizadas pelos docentes. As plataformas escolhidas para compor a pergunta 4 foram escolhidas após busca em diversas referências que versavam sobre principais plataformas utilizadas para ensino remoto, logo optou-se por listar as mais citadas (Alves, 2020; Rocha et al., 2020; Santos et al., 2020).

Tabela 4: Frequência do uso de cada plataforma no ensino remoto por ordem de resposta, uma vez que mais de uma plataforma pode ser usado.

\begin{tabular}{|c|c|c|c|c|c|c|}
\hline \multirow{2}{*}{ Plataforma } & \multicolumn{5}{|c|}{ Ordem de Resposta } & \multirow{2}{*}{ Total } \\
\hline & $\mathbf{1}^{\mathbf{o}}$ & $2^{\circ}$ & $3^{\circ}$ & $4^{\circ}$ & $5^{\circ}$ & \\
\hline Google Classroom & 4 & 84 & 33 & - & - & $121(62,4 \%)$ \\
\hline Google Meet & 167 & - & - & - & - & $167(86,1 \%)$ \\
\hline Moodle & 2 & 5 & 8 & 9 & & $24(12,4 \%)$ \\
\hline Outra & 9 & 7 & 20 & 8 & 7 & $51(26,3 \%)$ \\
\hline $\begin{array}{l}\text { Plataforma da instituição } \\
\text { de ensino }\end{array}$ & 5 & 15 & 21 & 6 & 2 & $49(25,3 \%)$ \\
\hline Zoom & 7 & 47 & - & - & - & $54(27,8 \%)$ \\
\hline
\end{tabular}

Fonte: Autores (2021). 
Gráfico 5: Plataformas digitais que os professores de Física entrevistados utilizaram para o desenvolvimento das aulas remotas.

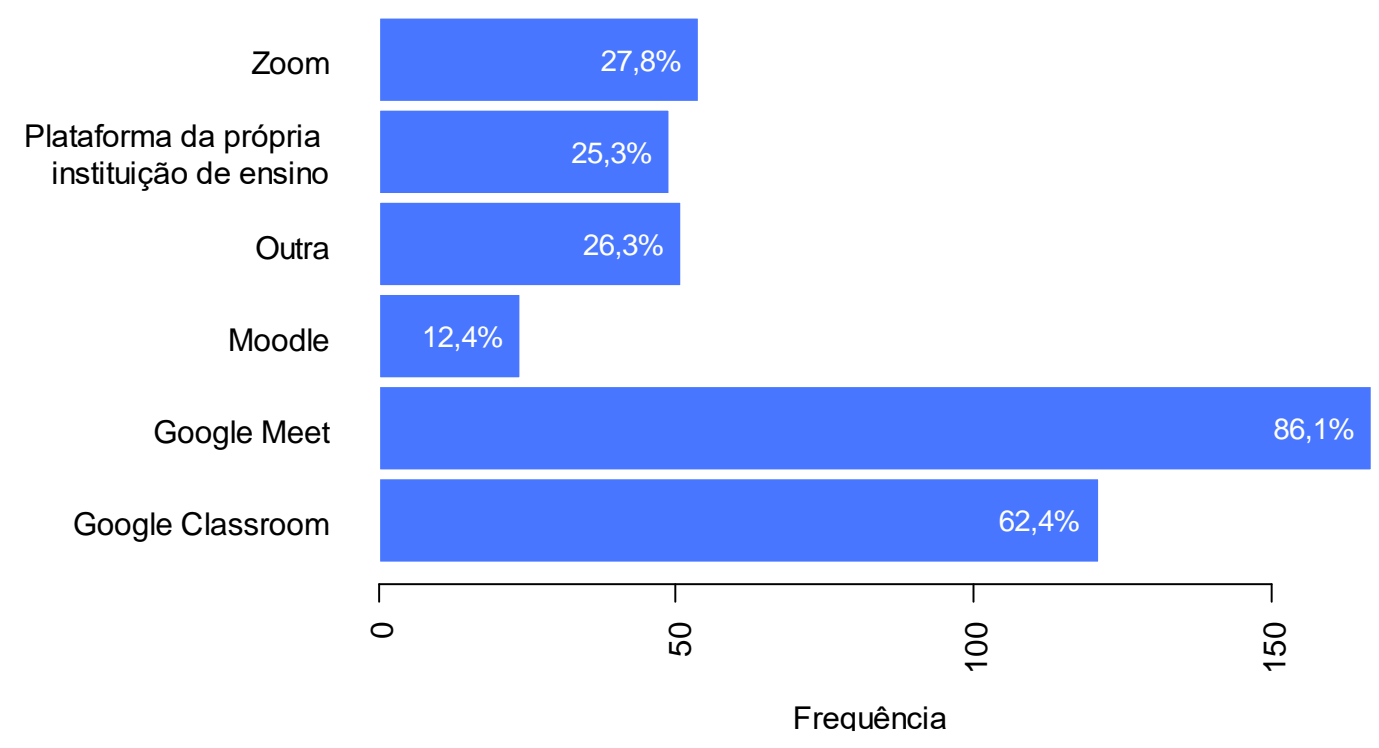

Fonte: Autores (2021).

A plataforma Google Meet figura entre as mais utilizadas em conjunto com o Google Classroom (Gráfico 5), acreditase que a escolha massiva por estas plataformas seja em função da gratuidade das mesmas, bem como o fácil acesso e manuseio. Analisando o percentual de respostas é possível constatar que os docentes, em geral, utilizam simultaneamente mais de uma plataforma, o que é justificável uma vez que algumas permitem reuniões on-line e outras têm como funcionalidade receber e enviar arquivos.

Pensando no desgaste que o ensino remoto poderia causar aos professores, estes foram questionados se necessitavam de mais tempo para preparar as atividades e/ou as aulas remotas se comparando ao tempo que gastavam para preparar as aulas e atividades presenciais. Uma taxa de $87 \%$ respondeu que o tempo de preparo das aulas remotas é maior se comparado ao tempo necessário para preparar as aulas presenciais, contudo, $68 \%$ afirmaram que o tempo de duração das aulas remotas é diferente (menor) do que das aulas presenciais.

O Gráfico 6 resume as opiniões dos entrevistados com relação à dinâmica das aulas remotas. 
Gráfico 6: Opiniões dos entrevistados com relação à dinâmica das aulas remotas.

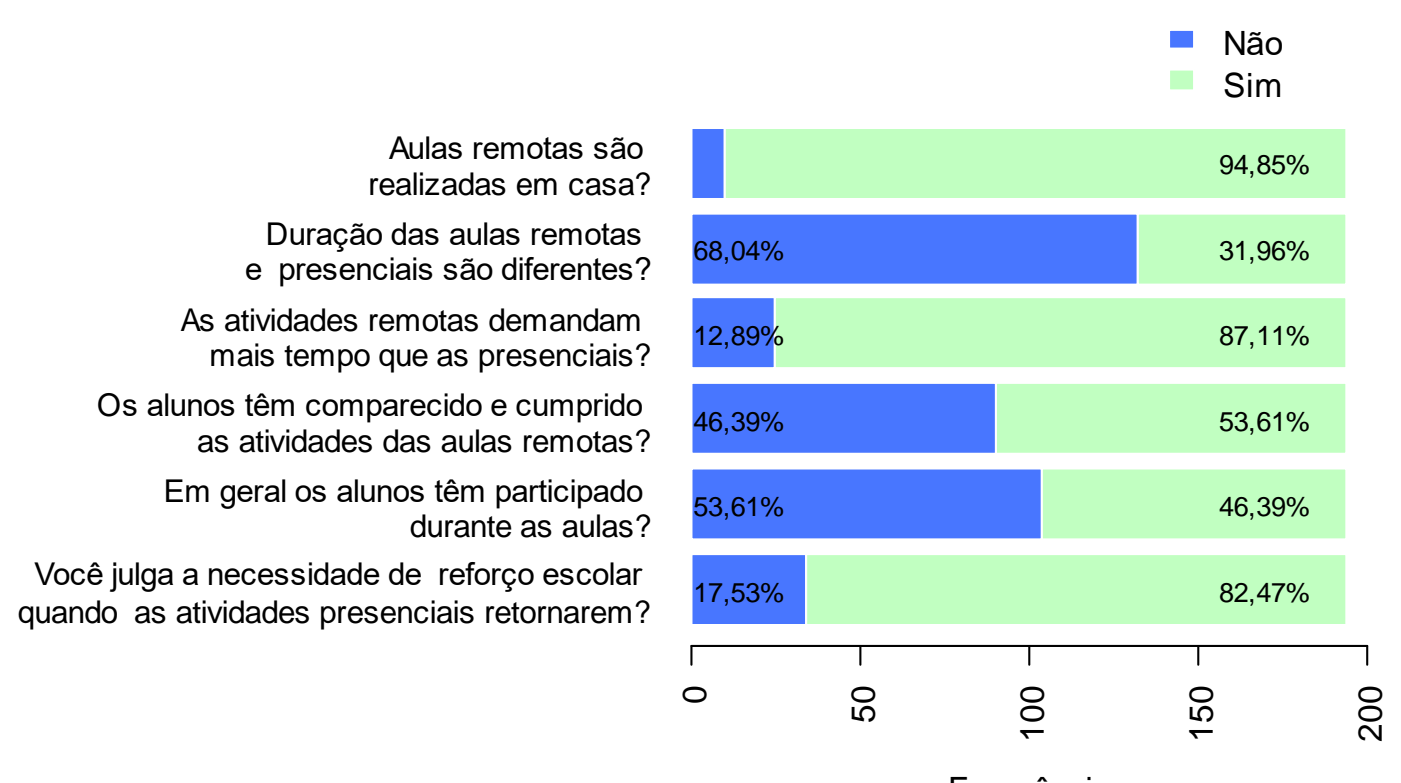

Frequência

Fonte: Autores (2021).

Quando os docentes entrevistados foram inquiridos se eles realizam as aulas remotas em casa por opção, obteve-se as respostas arroladas na Tabela 5.

Tabela 5: Respostas dos entrevistados sobre a opção de realizar suas atividades em casa.

\begin{tabular}{l|l}
\hline \hline Você tem realizado as aulas remotas em casa por opção? & $\begin{array}{l}\text { Frequência } \\
(\boldsymbol{\%})\end{array}$ \\
\hline \hline $\begin{array}{l}\text { Não (estou realizando minhas aulas na instituição que leciono a pedido da } \\
\text { mesma) }\end{array}$ & $19(9,79 \%)$ \\
\hline Sim (porém tenho a opção de realizá-las na instituição que leciono) & $1(0,51 \%)$ \\
\hline Sim (pois não é possível realizar minhas aulas na instituição que leciono) & $107(55,15 \%)$ \\
\hline Sim (porém tenho a opção de realizá-las na instituição que leciono) & $67(34,54 \%)$ \\
\hline \hline Total & $\mathbf{1 9 4 ( \mathbf { 1 0 0 } \% )}$ \\
\hline \hline
\end{tabular}

Fonte: Autores (2021).

Considerando que quase todos os docentes realizam suas aulas em casa eles foram questionados sobre a disposição de espaço físico e recursos adequados (lousa, mesa digitalizadora, boa conexão de internet, dentre outros) (Gráfico 7). 
Gráfico 7: Espaço físico e recursos utilizados pelos docentes.

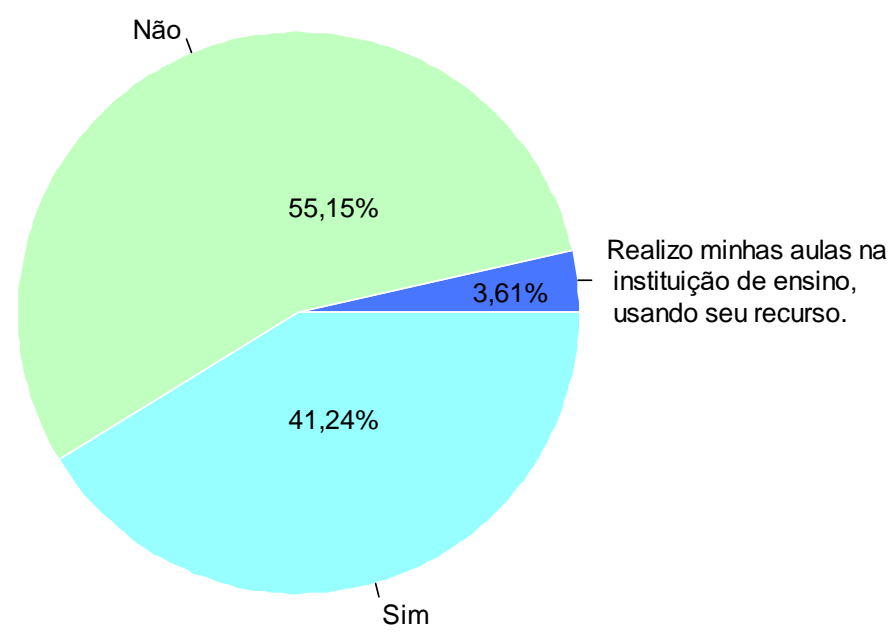

Fonte: Autores (2021).

Nesse sentido, a maior parte dos docentes $(55,15 \%)$ encontra alguma dificuldade para executar adequadamente suas atividades fora da presencialidade, seja em espaço físico ou recursos didático-pedagógicos.

Com relação ao comparecimento nas aulas on-line $54 \%$ dos entrevistados afirmam que os alunos não têm comparecido frequentemente e não cumprem regularmente as atividades propostas. Dentre os alunos que assistem às aulas, a maior parte não participa efetivamente quando são questionados (54\%) e em geral também não demonstram dúvidas ou questionam o professor sobre os conteúdos expostos.

Com base nas experiências quanto às aulas remotas e o processo formativo de ensino-aprendizagem, $83 \%$ dos docentes julgam que será necessário reforço escolar quando as atividades presenciais retornarem.

Quando questionados sobre seus sentimentos em relação à nova realidade imposta pela pandemia, os docentes responderam conforme o Gráfico 8.

Gráfico 8: Sentimentos dos professores de Física entrevistados quanto as aulas remotas.

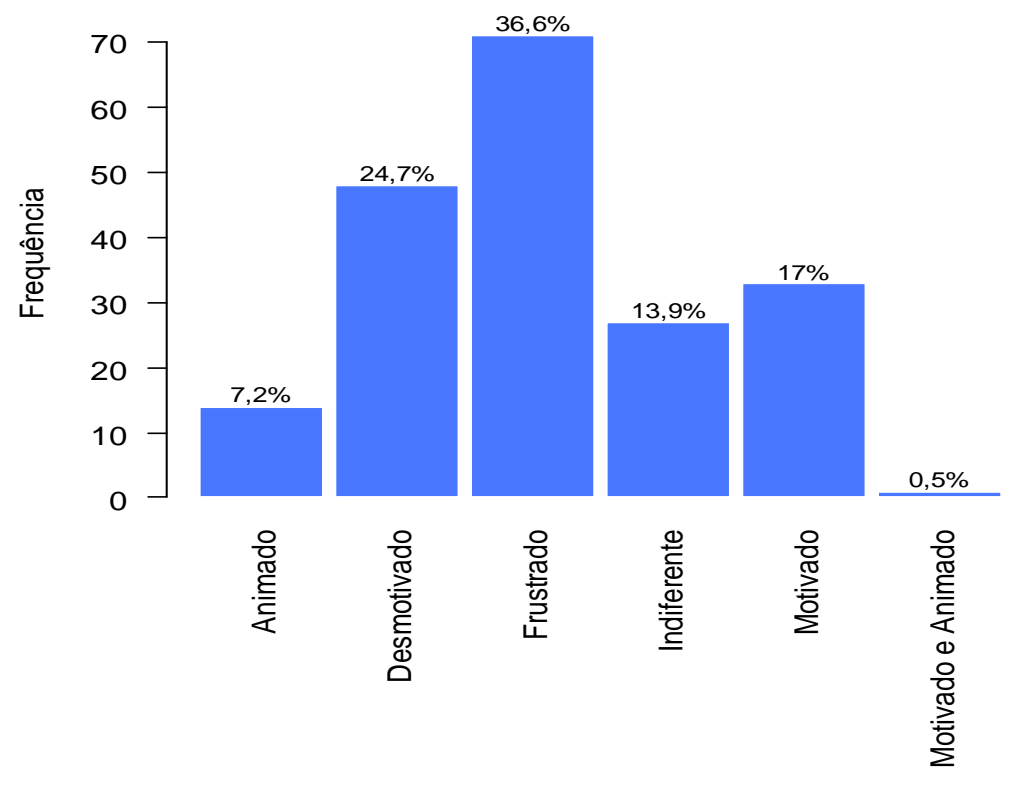

Fonte: Autores (2021). 
Observando os dados obtidos da pesquisa, verifica-se que apenas $25 \%$ (um quarto) dos docentes estão satisfeitos com o ensino remoto (motivados ou animados), $61 \%$ apresentam sentimentos de desmotivação ou frustração enquanto $17 \%$ estão indiferentes.

Um total de $14,43 \%$ avalia a experiência do ensino remoto on-line como ruim,58,76 \% razoável e 26,80 \% como boa, conforme o Gráfico 9.

Gráfico 9: Resultados das avaliações do ensino remoto na perspectiva do professor.

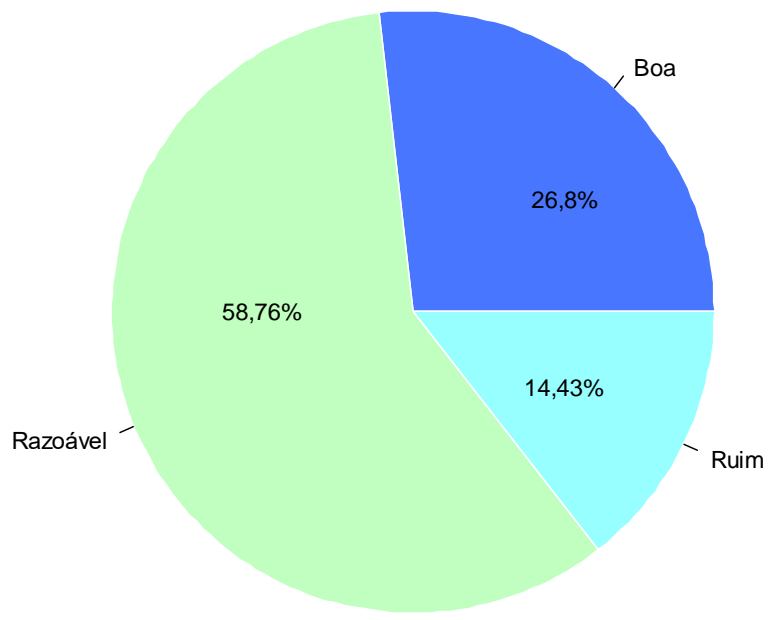

Fonte: Autores (2021).

Quando questionados sobre as perspectivas para o ensino pós-pandemia, isto é, se o ensino de Física poderá sofrer algumas mudanças didático-pedagógicas, passando a incorporar mais atividades on-line de um modo geral, $83 \%$ consideram que sim, $18 \%$ acreditam que o ensino voltará a ser como antes da pandemia, $91 \%$ afirmam que mesmo após o término da pandemia pretendem continuar utilizando alguma(s) da(s) ferramenta(s) digital(is) utilizadas durante as aulas remotas, para complementar suas aulas presenciais, como disposto no Gráfico 10.

Gráfico 10: Diagnóstico para o ensino de Física pós-pandemia.

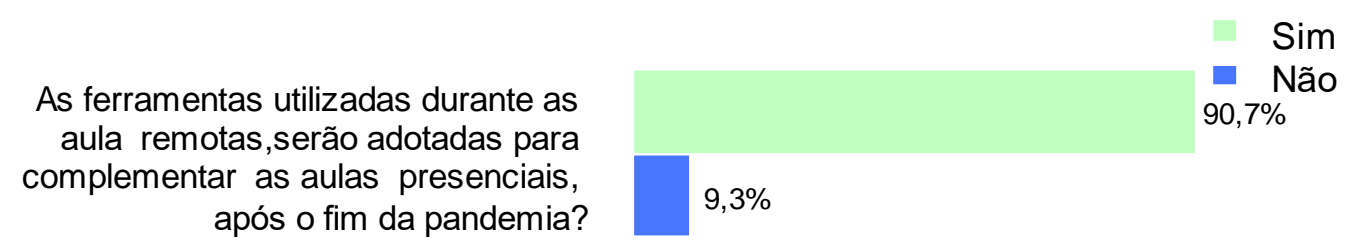

Após o fim da pandemia o ensino de física poderá sofrer algumas mudanças passando a incorporar mais atividades on-line de modo geral?

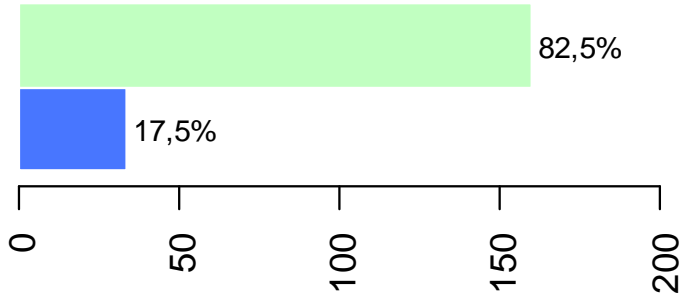

Frequência

Fonte: Autores (2021). 


\section{Considerações Finais}

O presente trabalho teve como objetivos compreender como ocorreu a transição do ensino presencial para o ensino remoto, como os docentes da área da Física se adaptaram a essa nova realidade e, ainda, como foi a participação dos alunos durante as aulas remotas. Assim, buscou-se mostrar o ponto de vista do docente de forma geral, ou seja, suas dificuldades quanto à preparação, execução e perspectivas futuras sobre as aulas remotas e o retorno das aulas presenciais.

De um modo geral, observa-se que a maior parte dos docentes não receberam treinamento, sendo necessário buscar por conta própria a qualificação necessária para executar da melhor forma possível suas aulas, os mesmos em sua maioria não dispõem de material ou espaço físico adequado o que, por sua vez, dificulta o preparo e a execução das aulas. Além disso, o não comparecimento e a falta de interação dos discentes afeta negativamente os docentes, sendo que mais de $50 \%$ dos entrevistados disseram que manifestam algum tipo de sentimento negativo no que diz respeito às aulas remotas, demonstrando sentimentos de desmotivação e frustração, bem como preocupação com o processo de aprendizagem uma vez que estes julgam que será necessário reforço após o retorno das atividades presenciais.

Contudo, mesmo que a realidade dos docentes mostra um cenário de dificuldades é possível constatar que o uso das plataformas digitais tem agregado no conhecimento dos professores visto que, a maior parte dos entrevistados, pretendem utilizar essas ferramentas mesmo após o retorno das aulas presenciais. Nesse sentido, pretende-se investigar futuramente quais recursos digitais os docentes continuaram utilizando em suas aulas pós pandemia, a fim de identificar como a mesma influenciou e mudou o ensino no que tange o uso da tecnologia em geral e, em especial, no ensino de Física.

Considerando a nova realidade que nos cerca concluímos que a repentinidade dos acontecimentos aliada a falta de investimento em qualificação por parte das instituições, assim como a evasão por parte dos alunos, pode ter sido os principais fatores que levaram os professores a se sentirem desmotivados e a terem dificuldades no processo de transição. Assim, uma vez que ainda se faz necessário o ensino remoto cabe aos docentes e instituições de ensino dialogarem a fim de buscarem em conjunto melhores ferramentas de ensino e formas de diminuir a evasão dos discentes.

\section{Referências}

Almeida, M. E. B. (2003). Educação a distância na internet: abordagens e contribuições dos ambientes digitais de aprendizagem. Educação e Pesquisa, 29(2), 327-40. https://doi.org/10.1590/s1517-97022003000200010

Alves, L. (2020). Educação remota: Entre a ilusão e a realidade. Interfaces Científicas Aracaju. 8(3), 348-65.Fluxo Contínuo.

Barbosa, A. M., Viegas, M. A. S. \& Batista, R. L. N. F. F. (2020). Aulas presenciais em tempos de pandemia: relatos de experiências de professores do ensino superior sobre as aulas remotas. Revista Augustus. 25(51). https://revistas.unisuam.edu.br/index.php/revistaaugustus/article/view/565

Brasil. Portaria No 343, de 17 de março de 2020. https:/www.in.gov.br/en/web/dou/-/portaria-n-343-de-17-de-marco-de-2020-248564376

Brasil. Portaria N ${ }^{\mathrm{o}}$ 544, de 16 de junho de 2020. https://www.in.gov.br/en/web/dou/-/portaria-n-544-de-16-de-junho-de-2020-261924872

Joye, C. R., Moreira, M. M, \& Rocha, S. S. D. (2020). Educação a Distância ou Atividade Educacional Remota Emergencial: em busca do elo perdido da educação escolar em tempos de COVID-19. Research, Society and Development, 7(9), 1-29. https://doi.org/http://dx.doi.org/10.33448/rsd-v9i7.4299 Joye,

Castro, E. A., \& Queiroz, E. R. de. (2020). Educação a Distância E Ensino Remoto: Distinções Necessárias. Revista Nova Paideia - Revista Interdisciplinar em Educação e Pesquisa, 2(3), 3-17. https://doi.org/10.36732/riep.v2i3.59

Dias, E., \& Pinto, F. C. F. (2020). A Educação e a Covid-19. Ensaio: aval. pol. públ. Educ., 28(108), 545-554.

Estrela, C. (2018). Metodologia Científica: Ciência, Ensino, Pesquisa. Editora Artes Médicas.

Houvèssou, G. M, Souza, T. P., \& Silveira, M. F (2021). Medidas de contenção de tipo lockdown para prevenção e controle da COVID-19: estudo ecológico descritivo, com dados da África do Sul, Alemanha, Brasil, Espanha, Estados Unidos, Itália e Nova Zelândia, fevereiro a agosto de 2020. Epidemiol. Serv. Saude, Brasília, 30(1):e2020513, 2021.

Godoi, M. (2016). O Perfil do Aluno da Educação a Distância e seu Estilo de Aprendizagem. EaD em Foco. 6. 10.18264/eadf.v6i2.383.

Godoy, A. S. (1995). Pesquisa Qualitativa: Tipos Fundamentais. Revista de administração de empresas. 35 (3). https://www.scielo.br/j/rae/a/ZX4cTGrqYfVhr 7LvVyDBgdb/?lang=pt\&format=pdf 
Research, Society and Development, v. 10, n. 11, e27101119293, 2021

(CC BY 4.0) | ISSN 2525-3409 | DOI: http://dx.doi.org/10.33448/rsd-v10i11.19293

Imprensa Nacional. https://www.in.gov.br/en/web/dou/-/portaria-n-544-de-16-de-junho-de-2020-261924872.

Oliveira, W. K., Duarte, E., França, G. V. A. , \& Garcia, L. P. (2020). Como o Brasil pode deter a COVID-19. Epidemiologia e servicos de saúde : Revista do Sistema Unico de Saúde do Brasil, 29(2), e2020044. https://doi.org/10.5123/s1679-49742020000200023

Marasca, A. (2020). O Ensino Remoto Emergencial e a Educação a Distância. Jornal da Universidade, https://www.ufrgs.br/jornal/o-ensino-remotoemergencial-e-a-educacao-a-distancia/.

Machado, D. P. (2020). Educação em tempos de covid - 19: reflexões e narrativas de pais e professores. Editora Dialética e Realidade, Curitiba. https://2b0ee3ca-fda1-4c02-aa8d-d6226f4481c2.filesusr.com/ugd/206e81_0a66ffe51a3a49eea20692bb92d96b64.pdf

Monteiro, S. S. (2020). (Re)inventar educação escolar no brasil em tempos da COVID-19. Rev. Augustus 25 (51).

Pereira A. S. et al. (2018). Metodologia da pesquisa científica. UFSM.

Quadros, D., Cordeiro, G. R. (2020). Pais, filhos e escola Ressignificação em tempos de pandemia. https://www.aredacao.com.br/artigos/133588/a-escola-dosfilhos-em-tempos-de-pandemia.

Reis, A. V. S.A, Amaro, D. \& Reis, F. (2020). Ensino remoto: o planejamento das aulas é, mais do que nunca, uma necessidade. https://revistaensinosuperior.com.br/planejamento-das-aulas/

Rocha, F. S. M., Loss, T. B., Almeida, B. L. C., Motta, M. S. \& Kalinke, M. A. (2020). O uso de tecnologias digitais no processo de ensino durante a pandemia da Covid-19. Interacções 16(55).

Santos, V. A., Dantas, V. R., Gonçalves, A. B. V., Holanda, B. M. W. \& Barbosa, A. A. G. (2020). O uso das ferramentas digitais no ensino remoto acadêmico: desafios e oportunidades na perspectiva docente. VII congresso nacional de educação. Educação como (re) Existência: mudanças, conscientização e conhecimento. Maceió.

World Health Organization - WHO. Coronavirus disease (COVID-19) pandemic https://www.who.int/emergencies/diseases/novel-coronavirus-2019 